\title{
Analysis of Air Flow and Heat Transfer in Ventilated Disc Brake Rotor with Diamond Pillars
}

\author{
Gorakh B. Kudal ${ }^{+*}$ and Mahesh R. Chopade ${ }^{\dagger}$ \\ ${ }^{\dagger}$ Department of Mechanical Engineering, MIT College of Engineering, Pune-411038, India
}

Accepted 15 June 2016, Available online 20 June 2016, Special Issue-5 (June 2016)

\begin{abstract}
The heat generated during braking operation is stored in brake disc and this heat is rejected to surrounding mainly by forced convection. Effective design of ventilated brake rotor is an essential to achieve proper cooling of braking system. The ventilated brake discs are available in various configurations such as radial type and pillared type brake rotors. It is found that thermal failure of brake disc is not only due to high temperature, but also due to high thermal stresses developed within rotor passages. The temperature distribution within vane passage of radial vane rotors is not uniform and it leads to high thermal stresses. Pillared rotors are alternative to radial vane rotors as they have more uniform temperature distribution within rotor passages. This topic mainly focuses on understanding of air flow and heat transfer characteristics of diamond pillared brake rotor. The CFD code is used to analyze and improve convective heat dissipation through passages of diamond pillared brake rotor. Validation is done for tapered radial vane (TRV) rotor, for which the experimental and numerical results are in good agreement. The modified configuration of diamond pillared brake rotor shows $11 \%$ improvement in convective heat transfer coefficient as compared to baseline design of diamond pillared brake rotor.
\end{abstract}

Keywords: Brake disc, ventilated, thermal failure, thermal stresses, diamond pillared rotor, CFD

\section{Introduction}

Braking system is an essential component of vehicle for its safety purpose. Braking system is mainly used to control and limit the vehicle speed as per the requirements. Frictional brakes are mainly classified into disc brakes and drum brakes. Disc brakes convert kinetic energy of vehicle into heat energy by pressing brake pad axially against a brake rotor. The drum brakes use shoes that are pressed against a drum. Under extreme condition such as descending a steep hill with a heavy load or a repeated high speed braking used in racing cars, drum brake would often lose their effectiveness and lead to brake fade. In this situation disc brakes are more suitable than drum brakes as they withstand in a very high temperature as compared to drum brakes. Long repetitive braking leads to temperature rise of various component of the vehicle brake system that reduces the performance of brake system. Therefore proper cooling of a vehicle braking system is an important safety issue.

The temperature of brake rotor may reach very high during braking operation. Therefore, the disc brake must be able to dissipate the heat as fast as possible to ensure higher life expectancy. The brake discs are solid and ventilated type. The ventilated discs

*Corresponding author: Gorakh B. Kudal are mainly used to improve cooling performance and its operation is similar as centrifugal impeller. Ventilated brake rotors are preferred over solid rotors due to their increased surface area of heat transfer and reduced mass. The air flow and heat transfer characteristics of ventilated disc brake rotors depend on various factors such as geometry of disc, air flow rate through rotor passages, passage turbulence intensity, rotational speed etc. Among all the above said parameters the aerodynamic flow characteristics highly dependent upon geometry of the disc and less dependent on rotational speed (D. Parish and D.G. MacManus, 2005). Therefore geometrical design of brake rotor is an important parameter which ensures proper cooling of braking system.

The ventilated brake rotors are mainly classified into radial type and pillared type brake rotor. The radial type brake rotors are easy to manufacture as compared to pillared type rotors. The material distribution is more uniform in case of pillared rotors, which provides resistance to crack propagation and significantly lower thermal stresses (Lisa Wallis, et al, 2002). It is also found that thermal failure of brake rotor is not only due to high temperatures, but also due to high thermal stresses developed due to large temperature gradients. The pressure, velocity and temperature distribution within vane passages of straight radial vane configuration rotors is not uniform 
which leads to high thermal stresses. Heat transfer from the rotor passages is symmetrical in case of pillared rotors. Hence, for modern high-speed vehicles, ventilated pillared rotors may be more appropriate as compared with straight radial vane configuration rotors (S. Manohar Reddy, et al, 2008). To improve the performance of a vented brake rotor, an understanding of air flow and heat transfer phenomena is very important. The flow through passages of the ventilated disc brake rotor is highly complex in nature and it can be better understood by using computational fluid dynamics (CFD). Numerical modeling can predict flow and heat transfer characteristics within passages of brake rotor and it can be used to improve cooling performance of brake rotor.

\section{Brake Disc Geometry}

Figure 1 shows the overall dimensions of diamond pillared brake rotor, which is considered for numerical analysis. The details about the rotor cross section are shown in figure 3 . The rotor has 36 equally spaced flow passages. The arrangement of diamond pillars in flow passages shows the more uniform material distribution in rotor passages. Pillared rotors were mainly developed for high performance application such as racing cars where temperature of rotor may reach very high. Pillared rotors have advantages of curved vane rotors which increases braking performance. The present study is carried out at $800 \mathrm{rpm}$ rotational speed, which is approximately 90 to $140 \mathrm{~km} / \mathrm{h}$ for a typical four wheeled vehicle.

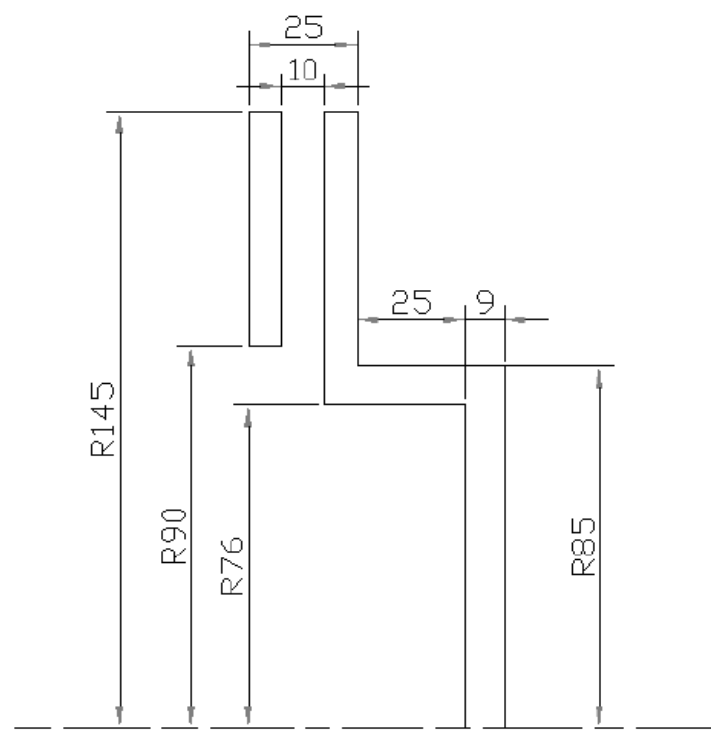

Fig.1 Disc Brake Rotor Geometry (Dimensions are in $\mathrm{mm}$ )

Modeling of diamond pillar brake rotor has been carried out using Creo Parametric 2.0. The baseline model of diamond pillar brake rotor is shown in figure 2. For numerical analysis due to rotational symmetry of brake rotor only a $20^{0}$ segment (two passages) shown in figure 3 is considered rather than complete rotor, which reduces computational efforts.

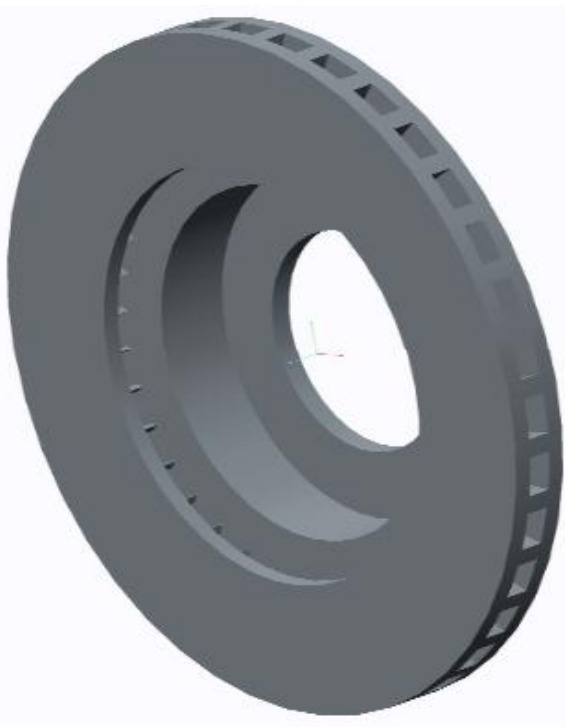

Fig.2 Diamond Pillared Brake Rotor

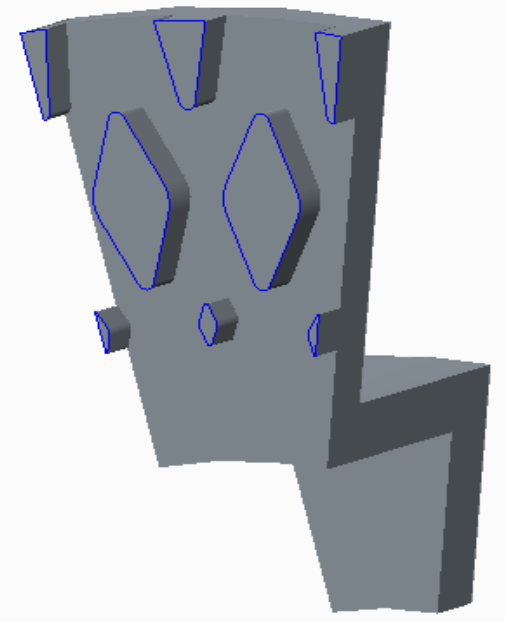

Fig.3 $20^{\circ}$ Segment of DP Brake Rotor

\section{Computational Modeling and Simulation}

The ICEM-CFD module of ANSYS is used for mesh generation and simulation is carried out in ANSYS Fluent. The main objective of this study is to understand the distribution of pressure, velocity and temperature within passages of diamond pillared brake rotor configuration. An attempt is made to enhance the convective heat transfer coefficient of diamond pillared brake rotor by understanding the air flow through passages of baseline design of diamond pillar.

\subsection{Meshing and Boundary Conditions}

The 3-D model of the diamond pillar brake rotor is imported in IGS format in ICEM-CFD for mesh 
generation. The brake rotor is treated as spinning in an infinite environment and hence open boundary conditions are applied at domain wall. At the inlet and outlet boundary of the domain, pressure of one atmosphere is specified. The computational domain is also a $20^{\circ}$ segment with radius $290 \mathrm{~mm}$ and length 120 $\mathrm{mm}$, which is large enough to avoid any effect on the flow through passages of brake rotor. Due to rotational symmetry periodic boundary conditions are applied to either side of the segment which represents entire rotor. Rotor walls are assumed at constant temperature. The details of boundary conditions and external domain are shown in figure 4.

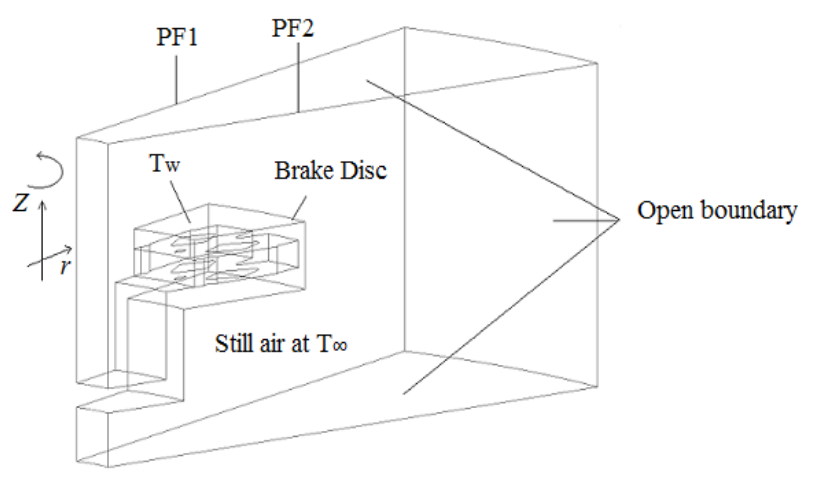

Fig.4 CFD Model with Boundary Conditions

In order to capture curved surfaces and wall properties, the model is discretized using hexahedral mesh elements. Fine mesh is employed near wall to capture both the velocity and thermal boundary layer. The hexahedral mesh model of diamond pillar is shown in figure 5 . The meshing is checked which gives a minimum angle of $36^{\circ}$ and minimum determinant of 0.65 . The meshing is also checked for other issues such as volume, surface orientation, minimum required quality in order to achieve correct results and better convergence.

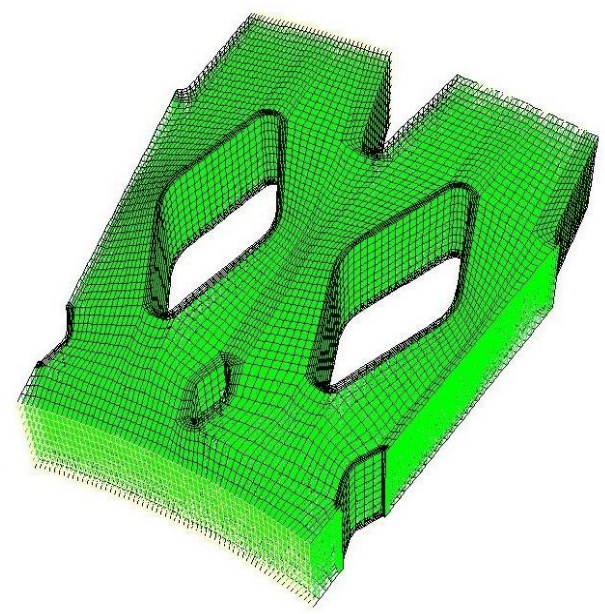

Fig.5 Hexahedral Meshing for DP Brake Rotor

The rotational speed of rotor is constant; therefore a moving reference frame is employed for the analysis. The flow of air is considered to be steady and incompressible ideal gas. Radiation and buoyancy effects are neglected. The surrounding pressure and temperature are assumed as $101325 \mathrm{~Pa}$ and $300 \mathrm{~K}$. The simulation is carried out by assuming rotor walls at constant temperature of $700 \mathrm{~K}$ for rotational speed of $800 \mathrm{rpm}$. The two fluid zones are created. The outer fluid is stationary, while inner fluid is rotating. These two fluid zones are interfaced by creating appropriate mesh interfaces available in ANSYS Fluent. The solid zone is not created as constant wall temperature condition is assumed for all rotor walls.

\subsection{Validation and Grid Independence}

The experimentation was performed on tapered radial vane (TRV) rotor. Firstly the brake disc was heated around $100^{\circ} \mathrm{C}$ by a surface heater of rating $1.0 \mathrm{~kW}$. A maximum temperature of $100^{\circ} \mathrm{C}$ was chosen to minimize heat lost by radiation. When temperature of rotor became uniform, the surface heater was removed and the brake disc was rotated at constant speed of $500 \mathrm{rpm}$. The rotor was driven by $2 \mathrm{hp}, 3$ phase induction motor, with speed control by variable frequency drive. The power is transmitted from motor to rotor via torque limiter and bearing assembly. Torque limiter is provided to avoid motor stall conditions while breaking. During rotation the temperature drop was recorded from $87^{\circ} \mathrm{C}$ for each minute by infrared temperature meter.

The convective heat transfer coefficient is calculated by using the law of energy conservation, which is given below,

Amount of stored heat lost by rotor $=$ amount of heat carried by air

$$
\mathrm{m} \mathrm{C}_{\mathrm{p}} \mathrm{dT} / \mathrm{dt}=\mathrm{h} \mathrm{A}\left(\mathrm{Tw}-\mathrm{T}_{\mathrm{atm}}\right)
$$$$
8.31 * 566 * 0.134=h^{*} 0.27 *(86.8-24.4)
$$

$$
\mathrm{h}=37.41 \mathrm{~W} / \mathrm{m}^{2} \mathrm{~K}
$$

The value of convective heat transfer coefficient obtained from CFD is $35.80 \mathrm{~W} / \mathrm{m}^{2} \mathrm{~K}$

The $\%$ deviation between experimental and CFD result is

$$
\begin{gathered}
\% \text { difference }=\frac{37.4-35.8}{37.4} \\
\% \text { difference }=4.30 \%
\end{gathered}
$$

The deviation between experimental and CFD result is about $4.30 \%$, which is in good agreement.

The grid independence study was carried out with grid sizes of 224000, 275000, 330000, 389000, 432000, 495000 and 581000 cells for baseline diamond pillared brake rotor configuration. The figure 6 shows value of convective heat transfer coefficient for corresponding grid size. It was observed that the variation in convective heat transfer coefficient becomes negligible for grid sizes more than 432000; therefore it was decided to use 432000 cells for all other configurations. 


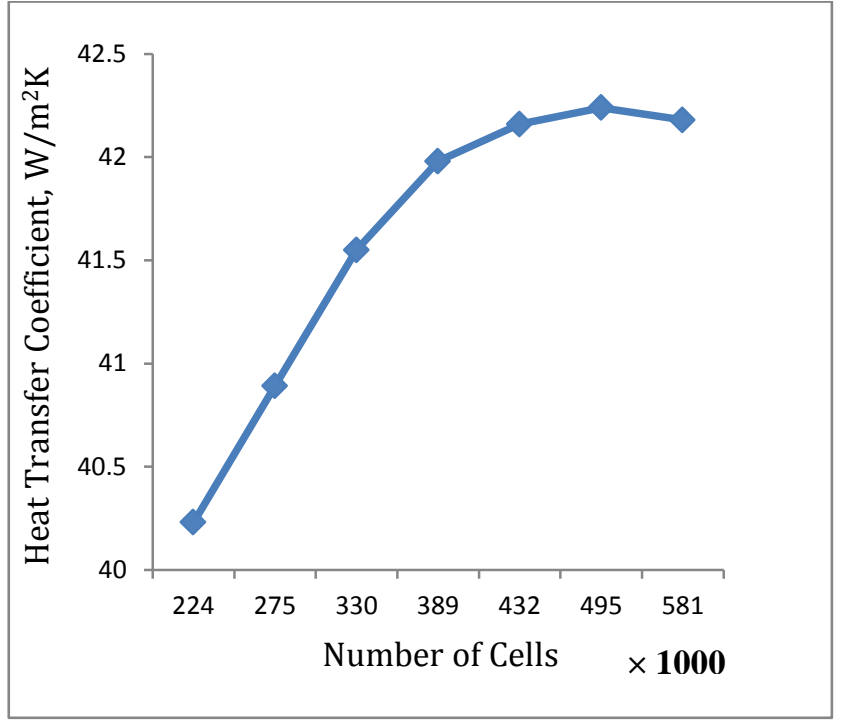

Fig.5 Convective heat transfer coefficients against grid sizes

\subsection{Modifications in Diamond Pillared Brake Rotor}

The modifications are done based on the flow analysis of baseline diamond pillared brake rotor. The specific objective is to reduce the size of recirculation area lies at upper side of diamond pillars. The recirculation regions reduce the air mass flow rate and hence convective heat transfer through rotor passages. To reduce the size of recirculation area all the diamond pillars are tilted in direction of rotation (clockwise direction).

The modifications in diamond pillars are done with the following assumptions:

i. The size of diamond pillars are kept constant and only their orientation is changed.

ii. The length of outer pillars can be changed to fit them at outer radius.

\subsection{Flow and Heat Transfer Analysis}

Figure 6 shows temperature, velocity streamlines and velocity vector plots at the passages of baseline diamond pillared brake rotor configuration. The analysis is carried out at $800 \mathrm{rpm}$ rotational speed and $700 \mathrm{~K}$ wall temperature.

From vector plot, it is seen that the recirculation region lies at upper side of diamond pillars. The recirculation region decreases air mass flow rate and the convective heat transfer through rotor passages. From temperature contour, it is seen that the rate of convective heat transfer is very low at the recirculation regions. Therefore it is necessary to decrease area of recirculation region lies within rotor passages. Based on this objective modifications are done by tilting all diamond pillars in clockwise direction.

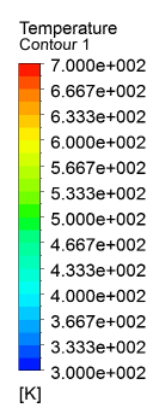

$[\mathrm{K}$

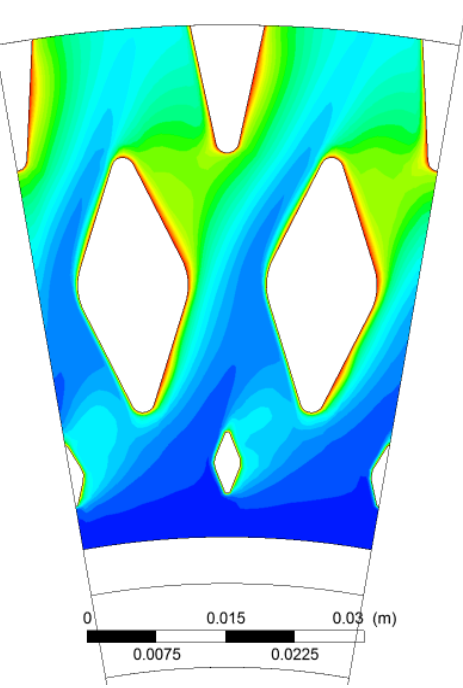

(a) Temperature Contour
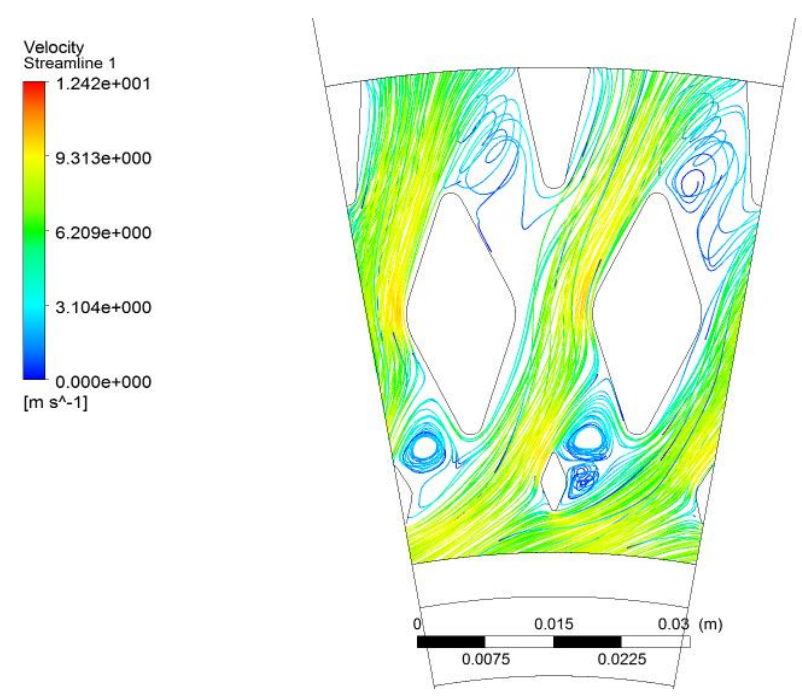

(b) Velocity Streamlines
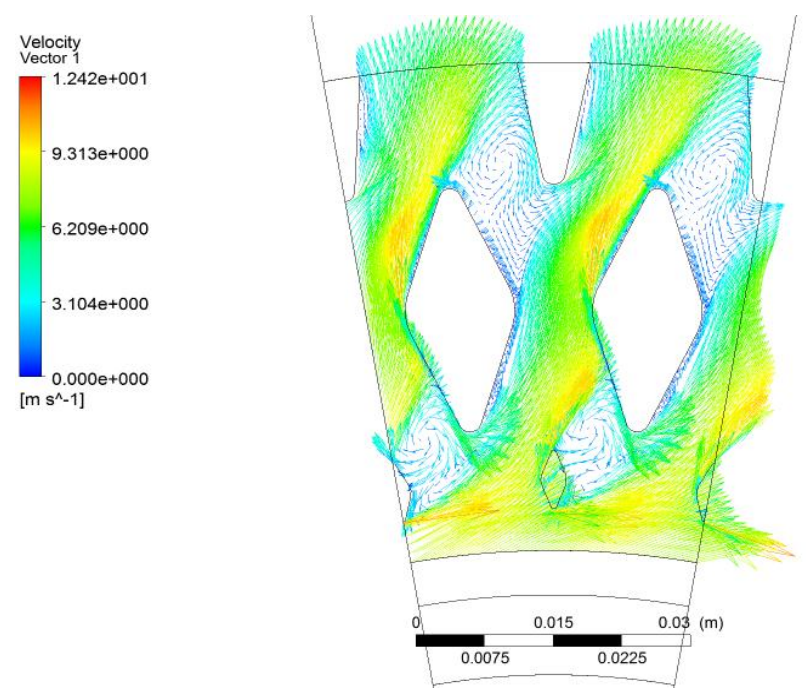

(c) Velocity Vector

Fig.6 Results for Baseline Diamond Pillared Brake Rotor 
The effect of inclination of pillars on convective heat transfer is analyzed by increasing angle of inclination of all pillars by $5^{0}$. In this way the new brake rotor designs with inclination given to all pillars viz. $5^{0}, 10^{0}$, $15^{\circ}$ and $20^{\circ}$ are studied. As angle of inclination increases the recirculation area lies at upper side of pillars decrease, which improves air mass flow rate and convective heat transfer through rotor passages. As we increase angle of inclination, the air flow becomes more re-aligned and reduces recirculation area. The velocity vectors for modified diamond pillar configurations are shown in figure 7. From vector plots, it is seen that with increase in angle of inclination of pillars from 0 to $20^{\circ}$, the area of recirculation zone decreases, which shows improvement in convective heat transfer through rotor passages. Beyond $20^{\circ}$ inclination, the reduction in recirculation area was very less, therefore further modifications were not considered.
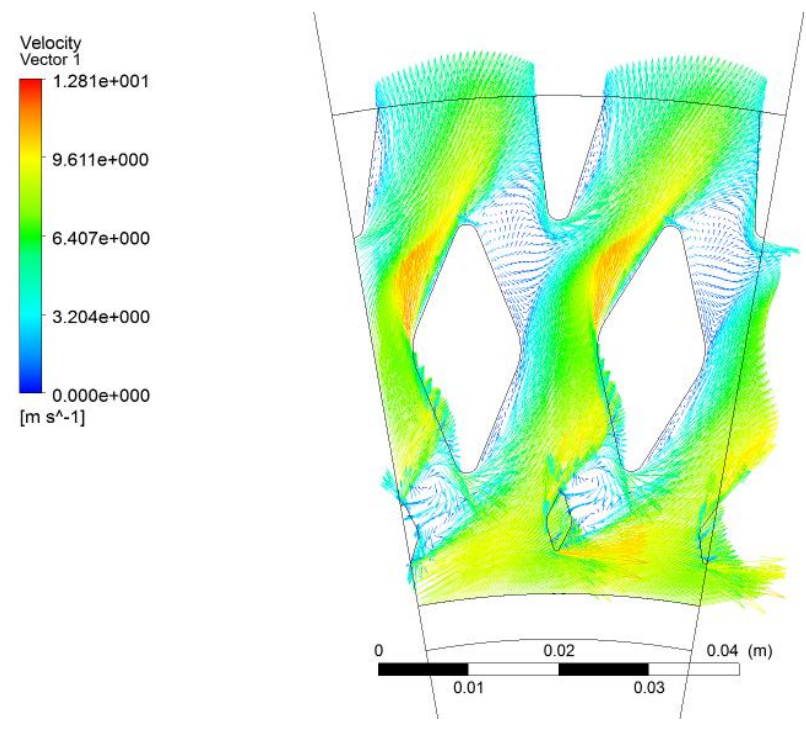

(a) $5^{0}$ Inclination
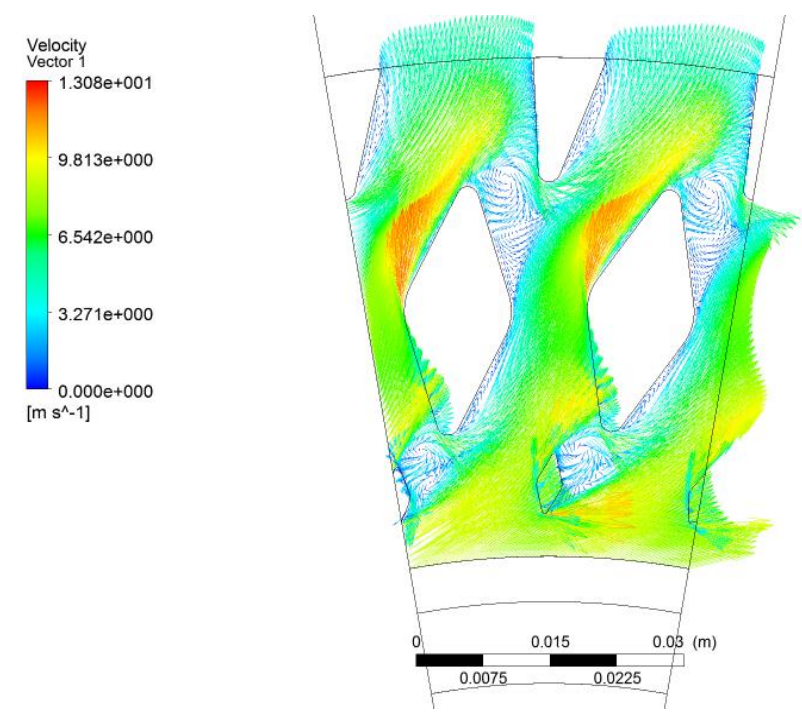

(b) $10^{\circ}$ Inclination
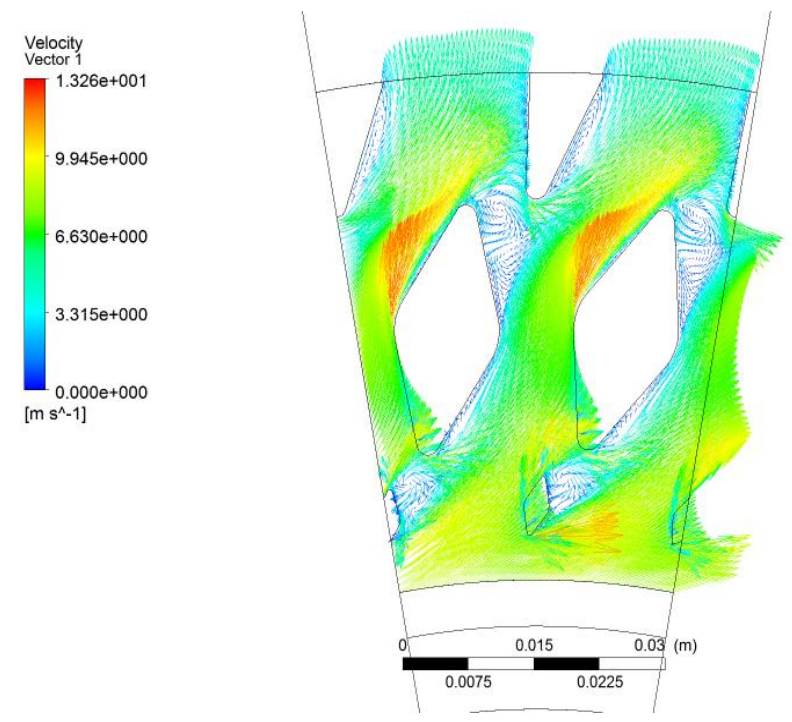

(c) $15^{0}$ Inclination
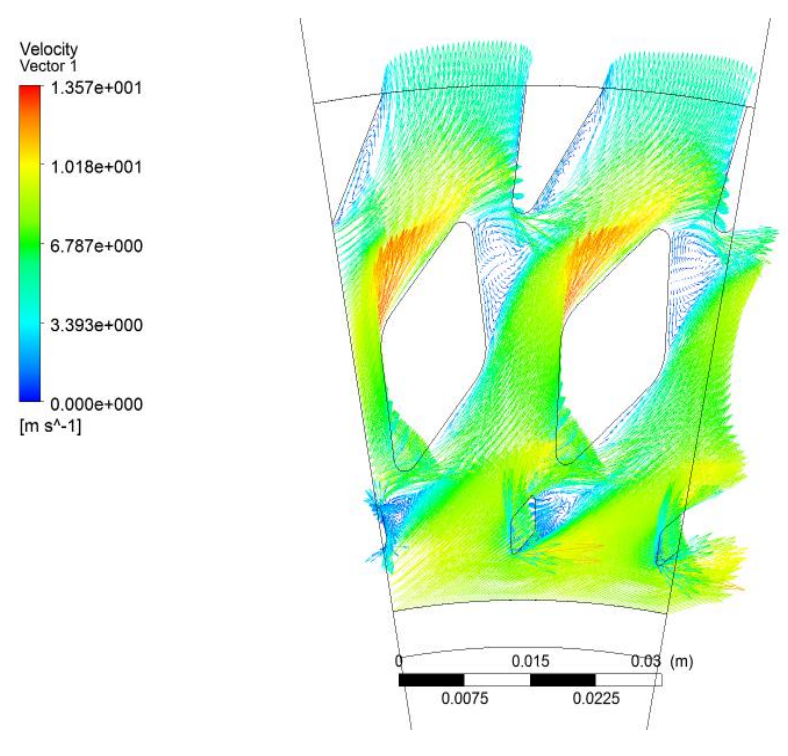

(d) $20^{\circ}$ Inclination

Fig. 7 Results for Modified Diamond Pillared Configurations

The table 1 gives information about improvement in convective heat transfer coefficient for modified geometries of diamond pillared brake rotor configuration along with baseline design.

The convective heat transfer coefficient increases around $11 \%$ at angle of inclination of $20^{\circ}$ given to all pillars. Beyond that the improvement in convective heat transfer coefficient is negligible, therefore further modifications are not considered. For $20^{\circ}$ inclinations design the mass flow rate increases by $16.11 \%$. The improvement in mass flow rate is due to reduction in recirculation areas presented in rotor passages. The reduction in recirculation areas is the key parameter to improve convective cooling performance of brake rotors. 
Table 1: Convective heat transfer coefficient and mass flow rate at $800 \mathrm{rpm}$ for modified diamond pillar brake rotor designs

\begin{tabular}{|c|c|c|c|c|}
\hline Brake Rotor Design & $\begin{array}{c}\text { Convective Heat } \\
\text { Transfer Coefficient, } \\
\mathrm{h}_{\text {conv }}\left(\mathrm{W} / \mathrm{m}^{2} \mathrm{~K}\right)\end{array}$ & $\begin{array}{c}\text { Relative Difference } \\
(\%)\end{array}$ & Mass Flow Rate (g/s) & $\begin{array}{c}\text { Relative Difference } \\
(\%)\end{array}$ \\
\hline Baseline & 42.16 & - & 1.08 & 2.109 \\
\hline $5^{0}$ inclination & 44.12 & 4.65 & 1.174 & 8.70 \\
\hline $10^{0}$ inclination & 45.02 & 6.78 & 1.215 & 12.50 \\
\hline $15^{0}$ inclination & 45.37 & 7.61 & 1.254 & 16.11 \\
\hline $20^{0}$ inclination & 46.80 & 11.00 & & \\
\hline
\end{tabular}

\section{Conclusions}

In the present study, the flow and heat transfer characteristics of diamond pillared brake rotor are studied by using computational fluid dynamics (CFD). Based on the above study, the following conclusions are drawn.

1) The recirculation regions in the flow passages reduce the convective heat transfer and air mass flow rate through rotor passages.

2) At the recirculation region the air becomes more stagnant which increases temperature at that location and it might promote the hot spots. Therefore it is necessary to reduce the area of recirculation region.

3) The area of recirculation regions has reduced by tilting all the diamond pillars in the direction of rotation of rotor. Due to this modification, the flow pattern became more re-aligned.

4) The modification has improved convective heat transfer coefficient about $11 \%$ for $20^{\circ}$ inclination provided to all pillars. Beyond that the improvement in heat dissipation was negligible.

5) Due to reduction in recirculation area, the air mass flow rate through rotor passages has also increased. At extreme for $20^{0}$ inclination of pillars, the air mass flow has improved by $16 \%$.

\section{References}

Reddy S., Mallikarjuna J., Ganesan V. (2008), Flow and Heat Transfer Analysis of a Ventilated Disc Brake Rotor Using CFD, SAE Technical Paper 2008-01-0822.

Lisa Wallis et al. (2002), Air Flow and Heat Transfer in Ventilated Disc Brake Rotors with Diamond and Tear-Drop Pillars, Numerical Heat Transfer, Part A, 41:643-655.
K. M. Munisamy, N. H. Shuaib, M. Z. Yusoff and S. K. Thangaraju (2013), Heat Transfer Enhancement on Ventilated Disc Brake Disc with Blade Inclination Angle Variation, International Journal of Automotive Technology, Vol. 14, No. 4, pp. 569-577.

Parish D., MacManus D. G. (2005), Aerodynamic Investigations of Ventilated Brake Discs, Proceedings of Institution of Mechanical Engineers, Part D: Journal of Automobile Engineering, 219, p.471-486.

Thundil Karuppa Raj Rajagopal et al. (2014), Numerical Investigation of Fluid Flow and Heat Transfer Characteristics on the Aerodynamics of Ventilated Disc Brake Rotor using CFD, Thermal Science, Vol. 18, No. 2, pp. 667-675.

Reddy S., Mallikarjuna J., Ganesan V. (2006), Effect of Vane Shape on Flow and Heat Transfer Characteristics of a Brake Disc, Proceedings of the 3rd BSME-ASME International conference on Thermal Engineering 20-22 December, 2006, Dhaka, Bangladesh.

F Talati and S Jalalifer (2007), Investigation of Heat Transfer phenomenon in a Ventilated Disc Brake Rotor with Straight Radial Vanes, Journal of Applied Sciences 8(20): 35833592.

A. Nejat, E. Mirzakhalili, M. Aslani and R. Najian Asl (November 2011),Heat Transfer Enhancement on Ventilated Brake Disc using Airfoil vanes, Journal of Thermal Science and Engineering, Vol. 3, No. 4, pp. 569579.

A.D. McPhee (2007), Experimental Heat Transfer and Flow Analysis of a Vented Brake Rotor, International Journal of Thermal Sciences, page 4,7.

Carlos Hannover Galindo-Lopez, Thesis on Optimization of Convective Heat Dissipation from Ventilated Brake Discs, May 2009.

Gautam Pulugundla, Thesis on CFD Design Analysis of Ventilated Disc Brakes, May 2008

Zhongzhe Chi, Thesis on Thermal Performance Analysis and Geometical Optimization of Automotive Brake Rotor, July 2008, pp. 57-85. 